\title{
A STUDY OF ATTITUDES OF COLOSTOMY PATIENTS TOWARDS A STOMA
}

\author{
SG MAJOLA, BB NTOMBELA AND BM ZUNGU
}

\section{The following 2 short research reports come from the Nursing Department, University of Zululand.}

The community from which the subjects were drawn all either live or work in or near the Ngwelezana area of KwaZulu Natal. This is a semi-rural, rapidly changing society situated very close to the busy industrial area of Richards Bay The reports are short, samples are of the convenience type and do not allow generalisation but nevertheless, together paint a small picture of patientlfamily needs in the area and give indication as to how nursing may help

\section{INTRODUCTION}

The researcher experienced that colostomy patients in the community are overprotected by their family members who viewed them as sick persons and do not permit them to continue with their household chores and daily activities. The patients are also stigmatised and labelled and this hurts and humiliates them especially if one has to shout in public about them. The colostomy patients are withdrawn, depressed and lonely.

The patients with a stoma have an increased need for reassurance and acceptance with love and understanding from those who care. The patients view the future from a different perspective desperately seeking recognition that they are infact the same person (Jones, 1981:53). Salter (1992:84) states that the significant others reaction and acceptance of his new condition will in turn affect the attitude of the patient lowards himself.

Salter (1992:48) states that some patients experience difficulties in coming to terms with a stoma. Their emotional and social effects include feelings of degradation, damage, isolation, restriction, mutilation and depression.

Therefore the purpose of the study is to explore the attitude colostomates have toward the stoma.

\section{RESEARCH METHOD}

A descriptive approach using an unstructured interview was used in order to identify the attitude of colostomy patients towards a stoma. Purposive sampling was used to obtain twenty respondents; 10 females and 10 males between 18 and 40 years of age. Age is of importance in this study because young adults are still socially active and may have a negative attitude towards a stoma.

\section{ETHICAL CONSIDERATIONS}

The permission to conduct a study was obtained from the Superintendent and the Senior Nursing Service Manager of the institution. Consent was obtained from the respondents and they were assured of confidentiality throughout the study.

Data were obtained through unstructured interviews. This was a method of choice because it allowed the subjects to verbalise their feelings freely and to remember facts accurately in a relaxed unhurried atmosphere.

Clarification and rewording of questions was made to meet the understanding of the respondents. Each interview lasted for about one hour to one and a half hours. An effort was made to ensure the reliability of data by concentrating solely on interviews with the identified subjects. The subjects were visited in their respective wards and interviewed privately in separate side wards

\section{RESULTS}

Eight males and six females maintained that they encounter problems when cleaning and changing the colostomy bag. They stated that sometimes they get ill-fitting bags which are either too big or too tight and state that these bags sometimes leak and humiliate them in public. They further stated that tight bags promote skin irritation which is painful and uncomfortable.

Sixteen subjects stated that due to their own experience they restrict themselves on food. Due to flatus and odour they avoided gas forming foods like cabbage and onions. They also avoided milk and mince meat since they have to change bags frequently which they do not like. They maintained that because of diarnoea they run out of bags.
Twelve respondents who were employed said that they feared losing their jobs due to sick leave and they viewed themselves as useless since they were sick.

Both males and females, including those who were single, raised a concern of fear of being rejected by their partners. They fear that bags may burst and leak during intercourse and mess up the bedlinen.

Eight males stated that they did have sex with their wives without problems. Four females said that they did not even try since they thought that the stoma might leak during the process of intercourse and humiliate them.

Eight females said that they had problems associated with clothing. They maintained that their choice was limited due to concealment of a bulky bag full of effluent or flatus and thus had to wear loose fitting clothing to accommodate a bag and therefore had negative attitude towards stoma.

Four males believed that the health professionals failed to get informed consent and that they only discovered after surgery that they were to use a bag for passing faecal matter. They maintained that they were told only that the doctors were to do an internal investigation of the bowel under anaesthesia since they had bowel obstruction.

Ten subjects stated that it would have been better if it was temporary since they cannot bear complications and physical problems like prolapse, retraction and the stigma attached. Two males described how they had been operated twice for correction of prolapse which is painful and uncomfortable.

Sixteen respondents mentioned that the family members were overprotective to them.

Eight females indicated that they were not allowed to do household chores like cleaning since they were sick. Two females maintained that they did not cook since they were regarded as "dirty and smelly" and were isolated. Three respondents said that their family members helped them when they were changing the bags.

Four females responded by saying that they had problems with those who were aware of their condition. 


\section{CONCLUSION}

It was clear that the colostomates had a negative attitude towards a stoma, caused by the complications and problems they encounter as colostomates.

These factors are:

- Leakages of stoma bags, flatus and smell which humiliates them in public and also stigmatized them.

- Rejection by the significant others which result in depression and isolation.

- Limitations and restriction on type and amount of food to take. They limit themselves on food like cabbages and milk since it promotes diarrhoea and flatus.

- The family members overprotect them. They are either ridiculed as dirty or not labelled as the same person as before.

- The society ridicules them in public and humiliates them.

- Maintenance of a stoma is costly. They buy deodorants to minimise odours and have frequent baths and change which males especially do not like.
- Loss of income to support their families if hospitalised for a long time.

- Colostomates who are working in public fear being noticed that they have bags.

- Colostomates had fear of indulging in sexual activity because they thought they were smelly and the bag might burst.

Even though the subjects had negative attitudes they did accept the colostomy bags since they have to live with them. They maintained that it helped them relieve the pain they experienced before surgery was performed but none of them showed any positive attitude towards a stoma.

\section{RECOMMENDATIONS}

There is need for further research on the attitudes of the colostomates towards their stoma. This will give a general attitude over a wide scale and aid nurses to see how best to help them.

A stoma is not a contra-indication to good health, sexual activities, full term pregnancy or raising a family. The psychological outcome is determined by age, personality background and disease including the facilities available for rehabilitation.
Each individual seems to experience difficult emotional problems, some encounter difficulties in accepting a stoma and adjusting to a change in body image (Bourke, 1984:5).

\section{BIBLIOGRAPHY}

JONES, A. (1981): Nursing case study on colostomy. Nursing Mirror 15, 50-51).

PRINGLE, L. (1984): Thriving with a stoma. Nursing Mirror 159.29 - 39).

SALTER, M.J. (1992): Difference between patients with conventional stoma compared to patients with conventional stoma followed by continent pain. Journal of Advanced Nursing 116.84-85).

WADE, B. (1990): Pyschological adjustment of colostomy patients at ten weeks and one year after surgery. Lournal of advanced nursing 15, 1297-1304.

Sindisiwe G Majola B.Cur Brenda B. Ntombela M.Cur Busi M. Zungu M. Soc. Sc. Dept. of Nursing Science University of Zululand 